CÓMO CITAR ESTE ARTÍCULO:

Enriquez, D. \& Durán, G. (2017). Las grandes presas en el río Yaqui (Sonora, México) y sus efectos socioambientales. Revista de Sociología y Antropología: VIRAJES, 19 (1), 165-188. DOI: 10.17151/rasv.2017.19.1.9

\title{
LAS GRANDES PRESAS EN EL RÍO YAQUI (SONORA, MÉXICO) Y SUS EFECTOS SOCIO-AMBIENTALES
}

\author{
DORA ELVIA ENRÍQUEZ LICÓN* \\ GUSTAVO LORENZANA DURÁN**
}

Recibido: 10 de diciembre de 2016

Aprobado: 21 de enero de 2017

Artículo de Investigación

\footnotetext{
** (1) ORCID: 0000-0003-2658-7770
}

*** (1) ORCID: 0000-0003-3980-1908 


\title{
Resumen
}

Objetivo. Analizar los factores presentes en el proceso de construcción de grandes presas sobre el río Yaqui entre 1934 y 1964. Metodología. Se revisó la historiografía más relevante sobre los usos y apropiación de tierra y agua en la región, analizándose varios cuerpos documentales de archivo y hemerografía en torno a la construcción de las presas, las posturas de los grupos sociales, las políticas públicas y el impacto al medio ambiente. Resultados. El presente trabajo expone el papel del Estado mexicano como constructor de las grandes presas de almacenamiento e impulsor de la agricultura bajo riego, generando con ello la creación de diversos paisajes y la contaminación por agroquímicos, entre otros efectos. Conclusión. En el valle del Yaqui, las modalidades en el uso y apropiación de los recursos tierra y agua, cuyo requisito fue la construcción de grandes presas, precipitaron intensas alteraciones en la naturaleza.

Palabras clave: Yaqui, La Angostura, El Novillo, Oviáchic, política agraria, impacto ambiental.

\section{THE LARGEST DAMS IN THE YAQUI RIVER (SONORA, MEXICO) AND THEIR SOCIO- ENVIRONMENTAL EFFECTS}

\begin{abstract}
Objective: To analyze the factors involved in the process of building large dams on the Yaqui River between 1934 and 1964. Methodology: The most relevant historiography on the use and appropriation of land and water in the region was reviewed, analyzing documentary archival bodies and several newspapers and periodicals concerning the construction of the dams, the positions of social groups, public policies and environmental impact. Results: This paper presents the role of the Mexican State as a builder of large storage dams and promoter of irrigated agriculture, thereby generating the creation of diverse landscapes and contamination by agrochemicals, among other effects. Conclusion. The modalities in the use and appropriation of land and water resources, which required the construction of large dams, precipitated intense changes in the environment of the Yaqui Valley.
\end{abstract}

Key words: Yaqui, La Angostura, El Novillo, Oviachic, agricultural policy, environmental impact. 


\section{Introducción}

L a cuenca del Yaqui en el noroeste mexicano tiene una extensión aproximada de $72.000 \mathrm{~km}^{2} \mathrm{y}$ comprende casi el $30 \%$ del territorio sonorense (mapa 1). Es una de las más extensas de México y también la más represada. La vasta infraestructura hidráulica construida en esta área durante la primera mitad del siglo XX tuvo como propósito impulsar el desarrollo agrícola del valle del Yaqui, cuya superficie irrigada comprende actualmente 232.944 ha. Para la década de 1960, el del Yaqui era uno de los más grandes distritos de riego norteños y fue considerado "el granero de México" (Cerutti, 2015, p. 105). Su arribo a tan privilegiada situación fue posible debido a las cuantiosas inversiones federales y a la ejecución de enérgicas acciones para vencer de manera definitiva la resistencia de los indios yaquis, que reclamaban la propiedad del territorio irrigado por el río más caudaloso de Sonora.

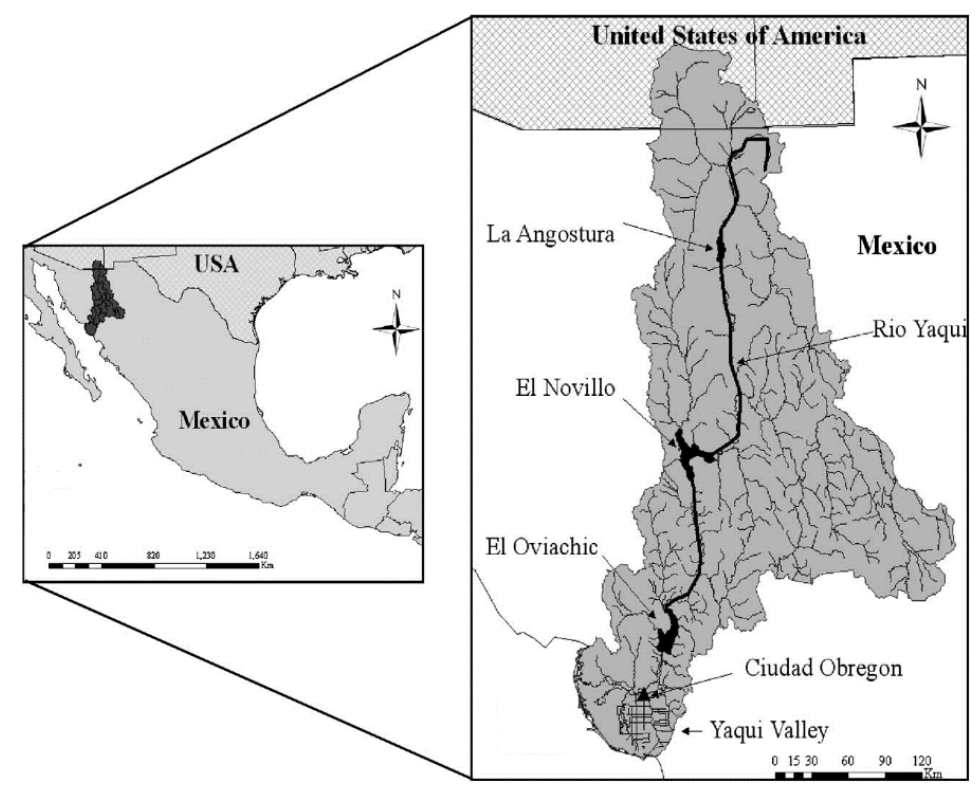

Mapa 1. Cuenca del río Yaqui.

Fuente: Grupo de Ciencias de la Tierra y Sustentabilidad del Instituto Tecnológico de Sonora. http://hidrologia-ambiental.com/investigacion/proyectos/ 
En el presente artículo analizamos el escenario histórico en que tuvo lugar el proceso antes mencionado; ponemos particular atención en describir el dilatado trecho temporal en que el fértil valle del Yaqui estuvo en manos de sus pobladores originarios. Enfatizamos también el rasgo predominante en la política agraria de Porfirio Díaz, a la que dieron continuidad los presidentes que gobernaron el país a partir de la Revolución de 1910, expresada mediante la construcción de tres grandes presas en el río Yaqui, obras que hicieron posible la expansión de la frontera agrícola y la emergencia compulsiva de una de las zonas más ricas del estado de Sonora (mapa 2).

Mapa 2. Estado de Sonora, México.

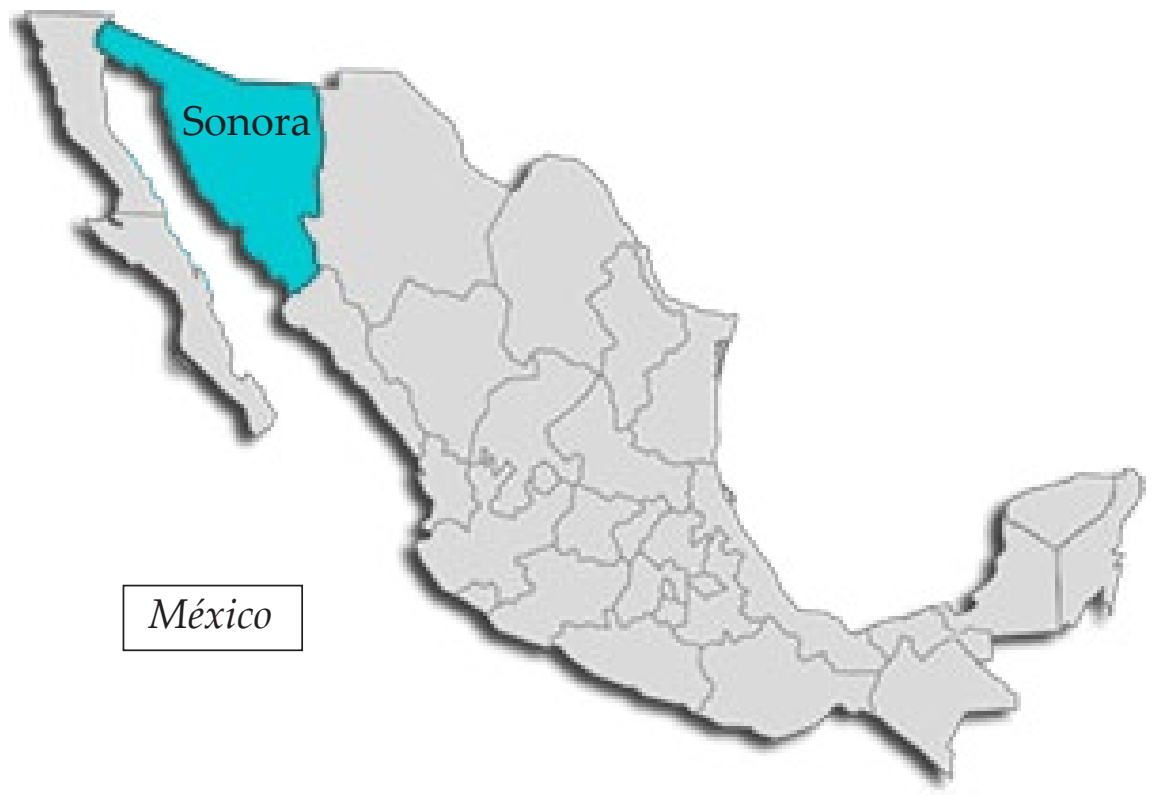

Fuente: cenapred.gob.mx

La agricultura de riego tiene la necesidad de acceder a las aguas de las corrientes superficiales aprovechables del entorno. Para ello, los dirigentes políticos y económicos se abocaron a construir obras hidráulicas, entre ellas, las presas. Éstas son "estructuras artificiales construidas sobre los ríos, cuyo objetivo es el de controlar el nivel del agua, regular su flujo o derivar sus caudales" (Sánchez y Eling, 2007, p. 107). Dos de las tres presas levantadas sobre el río Yaqui son para almacenamiento, la tercera se construyó fundamentalmente para la generación de energía eléctrica. En su construcción se utilizaron los materiales en boga en la época como el 
acero y el concreto reforzado. Las tres tienen una cortina de arco con sus vertedores.

En el presente artículo tenemos además gran interés en enunciar las secuelas socioambientales que acompañaron al anterior proceso, tomando en consideración los postulados de la historia ambiental ${ }^{1}$, abocada a estudiar las condiciones de deterioro en el medio ambiente como resultado de los distintos modos en que la humanidad ha orientado su intervención en los ecosistemas para apropiarse de sus recursos, mediante formas definidas e implementadas social e históricamente. Desde la perspectiva de los estudios ambientales cambia la concepción sobre la naturaleza; no se le ve más como aquel ámbito estable en el que el hombre debía extender su imperio, doblegándola -según postuló Francis Bacon- y se le encara de manera distinta, como una realidad compleja y vulnerable "en constante conformación y reconstrucción a lo largo del tiempo" (Castro, 2013, p. 118).

Worster (2008) distingue tres niveles en que opera la historia ambiental; el primero tiene que ver con la "comprensión de la propia naturaleza, tal como ha estado organizada y ha funcionado en tiempos pasados" (p. 42); un segundo nivel se asocia al campo socioeconómico y su relación con el medio ambiente; finalmente está la dimensión cultural, definida por las concepciones sobre la naturaleza, la ética, leyes, mitos y otras estructuras de significados. Advertimos que nuestra exposición está lejos de abarcar la vasta complejidad de la historia ambiental, si aceptamos que ésta es una "historia de muchas voces, de la diversidad de intereses y perspectivas" de la sociedad con la naturaleza (Escobar, 2013, p. 33). Nuestra contribución es modesta, aspira a hacer visibles algunos elementos de cambio asociados a la construcción de grandes presas en una región mayoritariamente desértica, cambios que demandan investigaciones más profundas.

\section{El valle del Yaqui y su río}

Históricamente, el río Yaqui ha tenido una gran significación. A su vera florecieron diversas sociedades prehispanas al amparo de fértiles vegas y planicies aledañas inundadas cada año por los desbordamientos que dejaban las lluvias veraniegas, así como en el somontano alto y bajo, donde se desarrolló una notable infraestructura de riego. La agricultura se practicó en esta región tres mil años antes de que los conquistadores españoles hicieran su aparición (Quijada, 2004; Montané, 2004). En las

\footnotetext{
${ }^{1}$ También llamada ecología política, ecología cultural, ecología histórica (Escobar, 2013, p. 14; Martínez Alier, 2014).
} 
diversas crónicas de exploradores, conquistadores, soldados y religiosos españoles quedó asentada desde el siglo XVI la imponente presencia del río. Hacia 1535 Alvar Núñez Cabeza de Vaca y sus acompañantes debieron esperar dos semanas para cruzar el Yaqui debido a "las muchas aguas que traía" (Montané, 2004, p. 99). Un par de años antes había llegado al río Diego de Guzmán, quien intentó tomar posesión de la tierra recién descubierta pero el jefe de los guerreros yaquis, según narran las crónicas, con la punta de su arco trazó una prolongada línea en la tierra, amenazando de muerte a los extranjeros si la cruzaban (Dabdoub, 1995, p. 21).

Posteriores intentos de someter a los indígenas del noroeste fracasaron, retardando la implantación del dominio español. Ante el nulo éxito de las armas, la corona española optó por una estrategia distinta, la conquista espiritual a cargo de misioneros jesuitas, quienes arribaron al Yaqui en 1615. Después de vencer militarmente al capitán de los soldados españoles, los yoeme ${ }^{2}$ aceptaron ser congregados en pueblos de misión bajo condición de que a su tierra no entrarían soldados. Los primeros misioneros conocieron bien el temple aguerrido de los yaquis; Andrés Pérez de Ribas se refiere a ellos como la nación más "populosa, belicosa y arrogante..." (Pérez, 1992, p. 283). Según su apreciación, el río "de hiaquis", por su abundante caudal, era como el Guadalquivir de Andalucía; naciendo en las altas serranías, corría:
por llanadas, y entre algunas lomas, por espacio de treinta leguas, hasta desembarcarse en el braço de Californias. En las doze ultimas, a la mar, esta poblada la famosa Nacion de Hiaquis, que goza de muchos valles, alamedas, y tierras de sementeras, las quales cuando el rio trae sus avenidas y crecientes, que son ordinarias casi cada año, las dexa regadas, y humedecidas para poderse sembrar de verano, sin [que] tengã necesidad de lluvias para sazonarse y gozarse sus abundãtes frutos. De suerte, que antes que entren las aguas, [que] suelen començar a principio de Julio, ya hã alçado sus semillas los indios, y esta es su principal cosecha; no obstãte que por tiempo de aguas suelen algunos volver a sembrar [...]. (Pérez, 1992, p. 284)

La alta productividad de las misiones yaquis permitió apoyar la evangelización en la Baja California y la fama de la fertilidad de sus suelos los hizo desde temprano muy codiciados; la presión se incrementó al ser expulsados los jesuitas en 1767 pero el reparto de tierras decretada en junio de 1769 por el visitador José de Gálvez fue de imposible cumplimiento en el Yaqui, aunque abrió el resquicio por donde se colaron las expectativas de

\footnotetext{
${ }^{2}$ Término con que se nombran a sí mismos los yaquis.
} 
colonos no indígenas exigiendo su derecho a poseer tan fértiles territorios. La laxitud que siguió a la expulsión de los padres ignacianos permitió a los yaquis apuntalar su autonomía y reforzar los elementos de su organización social; afianzaron también su sentido de pertenencia sobre la tierra y el río, hasta hacerlo factor indeleble de su identidad cultural (Padilla Ramos, 2016).

Cuando en el México independiente cambiaron las circunstancias políticas, incrementó la coacción hacia los indígenas y sus tierras; el siglo XIX atestiguó innumerables rebeliones yaquis, que continuaron las primeras décadas de la siguiente centuria. La gran significación que el término progreso tuvo para las élites políticas nacionales y regionales durante este lapso, matizó su hacer y etiquetó como enemigos a quienes no comulgaran con sus postulados, como fue el caso de los yaquis. Para doblegarlos de una manera definitiva fue precisa una estrategia combinada: guerra de exterminio y deportación. Al quedar vacíos los pueblos yaquis durante los primeros años del siglo XX, el gobierno federal protegió a los colonos que habían adquirido terrenos fraccionados por empresas privadas (Padilla, 2015a).

Carlos Conant y posteriormente la Compañía Constructora Richardson fueron, entre 1890 y 1924, los artífices del moderno Valle del Yaqui; disfrutando del apoyo gubernamental fraccionaron el amplio territorio, construyeron canales, vendieron terrenos y proyectaron grandes presas para dominar las broncas y caudalosas aguas del río Yaqui. Sin duda avanzaron en su propósito, pero la Revolución de 1910 cambió de nuevo las circunstancias; los yaquis (de Yucatán y del Valle) vislumbraron la oportunidad de recuperar sus tierras y se sumaron a la revolución al lado de Álvaro Obregón; al ver incumplidas sus promesas, una vez más tomaron las armas y una vez más fueron combatidos militarmente.

El desenlace del secular conflicto por tierras y aguas en el Valle del Yaqui ocurrió durante el gobierno de Lázaro Cárdenas, que en 1937 restituyó a los indígenas $485 \mathrm{mil} 235$ ha, garantizando su derecho a utilizar las aguas del todavía indómito río, pues dispondrían del 50\% de las aguas que almacenara la presa La Angostura, entonces en construcción (Lerma, 2014, pp. 255-56). Para entonces, sin embargo, estaba bien definida la política agraria de los gobiernos emanados de la revolución; la modernización agrícola ocupó un sitio privilegiado y perentorio. 


\section{Políticas públicas}

Se ha considerado que, en lo tocante al proyecto de modernización de la agricultura mexicana, no hubo grandes rupturas entre la última etapa del porfiriato y los gobiernos revolucionarios; en este lapso se orientó la política agraria al fortalecimiento de la agricultura de exportación. Es claro que los presidentes sonorenses Álvaro Obregón (1920-1924) y Plutarco Elías Calles (1924-1928) buscaron, más que repartir la tierra, fortalecer la pequeña propiedad; su "gran proyecto" consistió en mejorar las condiciones técnicas de la producción impulsando obras de irrigación, disponibilidad de crédito, organización de los productores, mejoramiento de semillas y adecuada comercialización (García Ugarte, 1995).

Al inicio de su gobierno, el presidente Obregón consideró que el acceso al agua por parte de los agricultores mexicanos era prioritario. En atención a tal primacía fue creada en marzo de 1921 la Dirección de Irrigación, cuyo objetivo fue construir obras de riego en diversos estados de la república mexicana. Así el Estado mexicano, además de ser el actor económico principal, pasaba a ser constructor de infraestructura hidráulica (Los Presidentes, 1966). La mencionada dirección desarrolló estudios en zonas susceptibles de ser irrigadas, tomó a su cargo varias obras y realizó análisis geológicos para el aprovechamiento de aguas subterráneas, perforando más de 20 pozos con éxito. Así mismo, elaboró la reglamentación para administrar el recurso hídrico, asunto toral pues la nueva normatividad iba a permitir en "lo sucesivo aprovechar racional y efectivamente las aguas de los ríos, lagos y, en general, las nacionales, mejor de lo que acontece en la actualidad y más equitativamente" (Ibíd., pp. 510 y 565).

De igual manera, Plutarco Elías Calles consideró que para solucionar el problema agrícola era preciso ampliar los sistemas de irrigación, pero además, incrementar la disponibilidad del crédito (García Ugarte, 1995). Durante su presidencia se creó la Dirección de Tierras, Colonización, Aguas e Irrigación, que sustituyó a la Dirección de Irrigación (Los presidentes, 1966, p. 686). Un paso significativo fue el nacimiento de la Comisión Nacional de Irrigación (CNI); el artículo 3 de la Ley sobre irrigación con aguas federales del 4 de enero de 1926 da cuenta de las tareas a su cargo, primordialmente proponer y construir obras de irrigación ${ }^{3}$. Asimismo, se aprobó el 10 de febrero del mismo año la Ley de Crédito Agrícola y en abril fue emitida la Ley de Colonización, mediante la cual se reglamentó el fraccionamiento de la propiedad privada con excepción de aquella que demostrara "una adecuada explotación agrícola" mediante modernas tecnologías (García Ugarte, 1995).

$\overline{{ }^{3} \text { Diario Oficial de la Federación, } 9 \text { de enero de 1926, t. XXXIV }}$, número 7, 99. 
El presidente Calles mostró su convencimiento de quela construcción de grandes presas sería uno de los pilares del crecimiento económico del país. Iniciaba así la modernización de la agricultura (Aboites, 1998) y se perfilaba la concentración de las tierras bajo riego en manos del Estado mexicano, tendencia que persistió durante el Maximato (1928-1935). En el gobierno de Emilio Portes Gil, la CNI recibió una buena inyección de fondos públicos con la encomienda de realizar diversos proyectos; destacó el gran interés de construir una presa de almacenamiento en la parte alta de la cuenca del río Yaqui (Los presidentes, 1966, p. 913).

El 6 de agosto de 1929 se aprobó la Ley de Aguas de Propiedad Nacional, así como su respectivo reglamento, emitido el 31 de enero de 1930. Un par de meses después, el nuevo presidente Pascual Ortiz Rubio dictó el decreto sobre adquisición de tierras en los sistemas de riego. Por su parte, el general Abelardo L. Rodríguez, en su carácter de presidente sustituto, encomendó a la Secretaría de Agricultura y Fomento una revisión de la Ley de Aguas para facilitar la acción del Estado en materia de energía hidráulica, considerada una de las bases en que se apoyaría "la estructura económica del futuro" (Ibíd., pp. 1066, 1193-4). Además de ratificar la preeminencia del Estado mexicano en materia de tierras y aguas, el presidente Rodríguez colocó el acento en el uso industrial del agua como fuente para generar energía eléctrica. El jefe del Ejecutivo federal expidió una nueva Ley de Aguas de Propiedad Nacional el 30 de agosto de 1934.

Al tomar protesta como presidente en noviembre de 1934, Lázaro Cárdenas afirmó que sus antecesores habían repartido tierras estériles, con nulos beneficios sociales y productivos; expresó que el trinomio de los recursos tierra, agua y grandes presas de almacenamiento constituía la ruta para mejorar las condiciones de vida de las "clases rurales" de México. Para concretar los estudios y los proyectos hidráulicos en marcha se ampliaron los fondos destinados a obras de irrigación; hacia 1936, los proyectos hidráulicos insignias de la CNI eran tres grandes presas: la del río Nazas en Durango, la del Yaqui en Sonora y la del río San Juan en Nuevo León (Ibíd., p. 54).

Los subsecuentes mandatarios, Manuel Ávila Camacho y Miguel Alemán Valdés, siguieron en la línea de considerar la agricultura como la más importante fuente de riqueza del país; el último de los mencionados subrayó que el bienestar de la Nación requería aumentar la producción agrícola y para lograrlo, era esencial acelerar la construcción de obras de riego, que atenuarían el impacto de las temporadas de sequía. Impulsó además una política de colonización mediante la cual "se abrirán nuevas tierras al cultivo en donde todos los mexicanos que lo deseen podrán contribuir con su esfuerzo, estimulado por el Estado, para aumentar la 
producción fincando sobre la tierra misma la grandeza de la República" (Ibíd., pp. 355-6). A partir del 1 de diciembre de 1946 las tareas anteriores quedaron bajo la responsabilidad de la Secretaría de Recursos Hidráulicos (SRH), que sustituyó a la CNI.

El presidente Adolfo Ruiz Cortines, por su parte, se comprometió a continuar las obras en curso para enfrentar la sequía que en ese tiempo se padecía y que según los reportes técnicos, se iba a prolongar. En su informe de 1954 expuso:

Cada día es más evidente nuestra urgente necesidad de obras hidráulicas. Los Gobiernos de la Revolución, desde 1926, dedican atención creciente a las obras de esta índole y venciendo innumerables obstáculos y proporcionando las mayores sumas del presupuesto, se ha logrado [incrementar] el promedio anual de hectáreas beneficiadas. (Ibíd., p. 558)

En 1957 se realizaron los estudios de los proyectos eléctricos de los ríos Yaqui (El Novillo) y Santiago, para satisfacer la demanda de energía del sector industrial y la población urbana en aumento. La utilización de la fuerza motriz del agua para generar energía eléctrica constituyó, también, uno de los pilares de la política hídrica del presidente Adolfo López Mateos, que colocó en primer plano a la CFE, institución responsable de ejecutar el Plan Nacional de Electrificación.

\section{Las grandes presas en Sonora}

El valle del Yaqui se vislumbró desde el siglo XIX como idóneo para albergar los ambiciosos proyectos federales de desarrollo agrícola, compartidos por los gobiernos estatales y agricultores. Habilitar amplias extensiones de tierra demandó grandes inversiones para controlar y administrar el recurso básico: el agua. Uno de los principales retos enfrentados fue el de contrarrestar las constantes e impredecibles crecientes del río Yaqui; sus copiosas avenidas provocaron numerosas inundaciones en el pasado. Iniciando el mes de enero de 1740, en plena insurrección, los yaquis presenciaron "la inundación más grande de la que jamás habían tenido noticia" según testimonio de un misionero jesuita, quien afirmó:

[...] con dificultad, se contará (de antes ni después) lo que, en esta ocasión, se vio: ... llegar a juntarse las aguas de este río de Hyaqui con las del río Mayo, distantes entre sí quarenta leguas. De modo que todo este espacio de uno a otro río estuvo, por dos semanas y más, 
hecho un mar, continuado éste en otras muchas leguas, por las bandas contrarias de ambos ríos". (Padilla Ramos, 2016, p. 7)

Una nueva inundación ocurrida el 16 de agosto de 1770 ocasionó "muchas muertes y desastres y acabó con casi todos los pueblos del río... desde el pueblo de Potam [su corriente] abandonó su curso para formar una nueva boca." Setenta años después, en 1840, el río varió nuevamente su curso, abriendo nuevo cauce entre los pueblos de Potam y Rahum, dejó "en seco su curso antiguo con gran asombro de aquellos pueblos..." (Dabdoub, 1995, p. 107). En 1868 ocurrió otra gran catástrofe provocada por las avenidas del Yaqui, fue "la creciente grande" que también afectó el río Mayo. De ahí que domar tan impetuoso caudal fuera prioritario, así como contar con la infraestructura pertinente para aprovechar cabalmente el agua.

En 1890, el empresario Carlos Conant proyectó excavar "grandes depósitos para almacenar el agua de las épocas de mayor escurrimiento y aprovecharlas en las de escasez"; su empresa quebró en 1904, pues justamente una inundación destrozó las obras de canalización existentes y la maquinaria (Dabdoub, 1995, p 314; Okada, 2000, p. 92). Posteriormente, la Compañía Constructora Richardson, con mayor capacidad financiera y proyectos más ambiciosos, calculó que el agua transportada anualmente por el río era suficiente para regar 260.000 ha, "siempre que esta cantidad de agua la llevara el río continuamente, pero no es así, pues no lleva ninguna durante los meses de mayo y junio, y muy poca en febrero, marzo y abril." El problema se aliviaría construyendo una serie de presas a lo largo del río, mediante las cuales se lograría el "regadío perenne" en el valle del Yaqui. La "gigantesca presa" proyectada inicialmente generaría asimismo electricidad para satisfacer la demanda energética de las empresas mineras del norte de Sonora (Dabdoub, 1995, pp. 314-5) ${ }^{4}$.

1. Tales planes fueron interrumpidos por la Revolución; en 1923 una gran inundación destruyó las obras en proceso de la Richardson ${ }^{5}$, además de equipo y material de construcción. En enero de 1926 fue expedida la Ley sobre Irrigación de Aguas Federales en concordancia con el artículo 27 constitucional. Bajo el argumento de que la Richardson no había cumplido su compromiso de construir una presa de almacenamiento, el gobierno federal dio por terminado el contrato en noviembre de 1927; la empresa pasó a ser administrada

\footnotetext{
${ }^{4}$ El magno proyecto de la Richardson no tenía precedente en América: "la zona de irrigación sería dos veces mayor que la del Imperial Valley de California, y la gran presa, mayor que la Roosevelt de Salt River, Arizona, y la Elephant Butte, Nuevo México, sobre el río Bravo" (Okada, 2000, pp. 106-107).

${ }^{5}$ Otra gran inundación, con grandes afectaciones en toda la región, había tenido lugar en 1914. (Okada, 2000, p. 136).
} 
por el Banco Nacional de Crédito Agrícola, mientras la CNI asumía el control sobre los futuros trabajos de irrigación en la zona, que en gran medida dieron continuidad a los estudios realizados por la compañía (Okada, 2000).

Apoyada por dos despachos de ingenieros norteamericanos y el Bureau of Reclamation en Estados Unidos, con una amplia experiencia por haber participado en la construcción de la presa Hoover en Nevada (Evans, 2006, pp. 57-8), la CNI comenzó los estudios para la edificación de una presa para el control de las avenidas en octubre de 1935, bajo la premisa de que dicha obra hidráulica estaría llamada a "convertirse en un emporio de riqueza y prosperidad para el estado de Sonora"6 pues permitiría habilitar 245 mil hectáreas a la agricultura intensiva en la margen izquierda del río Yaqui y 55 mil en la margen derecha. El sitio que resultó más conveniente fue el conocido como La Angostura, cercano al pueblo de Óputo (hoy Villa Hidalgo), cuyos pobladores se dedicaban a la agricultura aprovechando tierras ubicadas a ambos lados del Yaqui. El 31 de octubre de 1935 se convocó públicamente a compañías constructoras para realizar la obra ${ }^{7}$, pero la alta inversión demandada desalentó los empresarios privados; la obra fue emprendida por la CNI iniciando los trabajos en enero de 1936.

El embate inicial sobre el medio fue la apertura del camino del lugar llamado Tajo a La Angostura, abriéndose más de $50 \mathrm{k}$ en la parte este de la Sierra Madre Occidental a $1200 \mathrm{msnm}$, que demandó el levantamiento de tres puentes, concluyendo los trabajos en julio de 1937. Fue inherente a tales obras la destrucción de la flora originaria y el desplazamiento o eliminación de especies animales. El campamento se instaló en unas lomas ubicadas a 255 metros de la margen derecha del río Bavispe, utilizándose para ello la madera de la zona aledaña, así como para realizar las actividades inherentes a la gran obra hidráulica, realizadas entre enero de 1937 y febrero de 1941.

El avance de los trabajos se dio a conocer en las páginas del diario hermosillense El Imparcial, que publicó el 1 de septiembre de 1940: “El más grande y sensacional paso del progreso de Sonora es incuestionablemente la construcción de la monumental presa Angostura... con la cual se irrigarán unas trescientas mil hectáreas de las mejores tierras de este estado". Varios meses después, los funcionarios de la CNI afirmaron que obras de tal envergadura eran una muestra de la "intensa lucha contra los elementos opuestos por la naturaleza" ${ }^{8}$. La Angostura comenzó a captar agua el 21 de julio de 1941, aunque el llenado de su embalse llevó varios años.

\footnotetext{
${ }^{6}$ Archivo Histórico del Agua (en adelante AHA), Fondo: Consultivo Técnico, caja 342, expediente 2891.

${ }^{7}$ AHA, Fondo: Consultivo Técnico, caja 852, expediente 8014.

${ }^{8}$ El Imparcial, 13 de noviembre de 1940.
} 
Tenía apenas dos años operando cuando los técnicos de la CNI realizaron estudios aguas abajo con el propósito de localizar el sitio adecuado para construir una nueva presa reguladora. ¿Por qué una segunda gran obra hidráulica sobre el río Yaqui? El motivo fue la gran distancia entre La Angostura y las tierras bajo riego en el valle del Yaqui, estimada en $360 \mathrm{~km}$. El lugar elegido fue el estrecho formado por las colinas conocidas como Oviáchic y La Cantera, cercano al pueblo de Buenavista. En mayo de 1943, la CNI ratificó el sitio como el más propicio para la construcción de la presa reguladora, pues dicho lugar contaba con los recursos pétreos demandados por una obra de tal magnitud. Además, en la margen izquierda del río Yaqui el terreno cumplía con las condiciones apropiadas para la apertura de un canal principal. La nueva presa El Oviáchic reduciría el tiempo en que el recurso hídrico estaría disponible, pues la llegada del agua embalsada en La Angostura tardaba entre 5 y 7 días para llegar a la bocatoma del canal principal ${ }^{10}$; con la nueva presa, la distancia se redujo a sólo 12 kilómetros ${ }^{11}$. La colocación de la primera piedra que dio el banderazo a la construcción de la presa ocurrió el 16 de noviembre de 1946.

El 9 de enero del año siguiente la SRH -de reciente creaciónpublicó la convocatoria para construir la presa. La empresa ganadora fue Urbanizaciones, S. A.; el inicio de la construcción se programó para el 12 de julio de 1947 y su conclusión para el 12 de enero de $1952^{12}$. El área del vaso abarcaba 15 mil hectáreas; la capacidad de almacenamiento se estimó en tres mil millones de metros cúbicos ${ }^{13}$. El costo proyectado (233 millones 500 mil pesos) sería financiado por el gobierno federal; la SRH manifestó que sería "una de las más importantes en la República mexicana tanto por las características de la obra como por la zona que beneficiará con el riego ${ }^{14}$." La inversión estaba plenamente justificada por los trabajos a realizar pero también porque, al quedar habilitada, "las regiones del Yaqui y Mayo quedarán unidas formando así la unidad agrícola más grande de América". La presa El Oviáchic fue inaugurada por el presidente Miguel Alemán Valdés el 15 de octubre de 1952.

Sin duda la construcción de las dos grandes presas sobre el río Yaqui, así como otras obras de infraestructura hidráulica impulsadas en la época y financiadas con recursos federales ${ }^{15}$, hicieron posible la "época de oro" de

\footnotetext{
${ }_{9}^{9}$ AHA, Fondo: Consultivo Técnico, caja 342, expediente 2891.

${ }^{10}$ El canal principal y las bocatomas fueron construidos por la Sonora, Sinaloa Irrigation Company de Carlos Conant Maldonado.

${ }^{11}$ El Imparcial, 16 de septiembre de 1946

${ }^{12}$ AHA, Fondo: Consultivo Técnico, caja 342, expediente 2891.

${ }^{13}$ El Imparcial, 16 de septiembre de 1947.

${ }^{14}$ El Imparcial, 16 de septiembre de 1947.

${ }^{15}$ Entre 1936 y 1955 se construyeron las presas de almacenamiento La Angostura en el río Bavispe: 1942,
} 
la agricultura comercial en Sonora. No obstante, hacia la década de 1960 el modelo agroexportador llegó a su límite, entonces gobierno y empresarios promovieron un nuevo modelo de desarrollo basado en la industria, lo que hizo aflorar la necesidad de incrementar la disposición de energía eléctrica y tarifas más accesibles ${ }^{16}$. La CFE inició operaciones en Sonora hacia 1950, la generación dependía de plantas termoeléctricas ubicadas en Guaymas, Ciudad Obregón y Hermosillo, estimándose la producción en 57.000 kW. Para incrementar tal cifra se aprovecharon dos presas ya en operación para instalar plantas hidroeléctricas: El Oviáchic en el río Yaqui ${ }^{17}$ y El Mocúzari en el río $\mathrm{Mayo}^{18}$.

No obstante, esa energía era insuficiente para los planes de crecimiento industrial; fue preciso buscar nuevas alternativas. En 1956 se evaluó la posibilidad de establecer en el río Yaqui una tercera presa entre las dos anteriores, para generar energía eléctrica ${ }^{19}$. El proyecto fue aprobado por el presidente Adolfo Ruiz Cortines; en marzo de 1958 la prensa local dio a conocer que iniciaba la ejecución de la primera fase de la obra, informándose que su capacidad sería de 4.478 millones de metros cúbicos, se instalarían dos unidades de $45.000 \mathrm{~kW}$ cada una para ser unidas al sistema interconectado de las termoeléctricas de Guaymas y Ciudad Obregón, así como a las hidroeléctricas del Oviachic, Mocúzari y la del Fuerte, en construcción para esa fecha ${ }^{20}$.

El proyecto tuvo continuidad con el presidente Adolfo López Mateos quien, como candidato, hizo alusión a la gran demanda de energía eléctrica ocasionada por el desarrollo agrícola, ofreciendo que impulsaría de inmediato la ampliación de la termoeléctrica de Guaymas y la ejecución de El Novillo ${ }^{21}$. Tales acciones armonizaban con su Plan Nacional de Electrificación, en cuyo avance fue fundamental el concurso de la CFE. Así, entre 1958 y 1964 se ejecutó en la parte media del emblemático río Yaqui la construcción de la presa y planta hidroeléctrica El Novillo por la CFE, que hizo posible la integración de un sistema regional conectado al sistema eléctrico nacional. El Sistema Sonora-Sinaloa -como se le conoció-

\footnotetext{
Oviáchic en el Yaqui: 1952, Mocúzari en el Mayo: 1951, Abelardo L. Rodríguez en Hermosillo: 1948 y Cuauhtémoc sobre el río Altar: 1950. Así mismo, se abrieron 1300 pozos que, en conjunto, permitieron irrigar 335 mil has. por gravedad y 170 mil por bombeo en los valles del Mayo, Yaqui, Hermosillo y la región de Altar (Cárdenas, 2008, p. 184).

${ }^{16}$ El Imparcial, 26 de noviembre de 1958.

${ }^{17}$ El Imparcial, 7 de abril de 1958.

${ }^{18}$ Declaración del Sr. José G. Gutiérrez, presidente de Canacintra en Sonora. El Imparcial, 7 de abril de 1958. Ver también Cárdenas $(2008,184)$.

${ }^{19}$ Memorándum núm. 11.0548, 28 de junio de 1956. Archivo Histórico del Agua (AHA) Fondo Documental Aguas Nacionales. Caja 3890. Expediente 62776. Legajo 1.

${ }^{20}$ El Imparcial, 12 de marzo de 1958.

${ }^{21}$ Discurso pronunciado por Adolfo López Mateos. La Opinión, 21 de abril de 1958.
} 
fue considerado uno de los más importantes de la República. Sus líneas de transmisión se extendieron desde Hermosillo hasta Culiacán, con una longitud aproximada de $650 \mathrm{~km}^{22}$.

Además de la apertura de caminos y establecimiento de los campamentos ${ }^{23}$, al despuntar agosto de 1962 iniciaron "los primeros colados en el desplante de la cortina, así como en la obra de toma y el vertedor ${ }^{24}$." Para enero del siguiente año estaban ya concluidos los caminos y muy avanzada la ejecución de la cortina, el vertedor, las obras de toma y la casa de máquinas ${ }^{25}$. Para junio de 1964 se habían instalado las "poderosas turbinas japonesas 26 ". En octubre la hidroeléctrica se sometió a prueba y resultó exitosa, el 12 de noviembre de 1964 "la gigantesca hidroeléctrica" fue inaugurada por el presidente Adolfo López Mateos ${ }^{27}$; se trataba de la presa más alta de su tipo en América Latina y la primera que se construyó en el país de tipo arco-cúpula ${ }^{28}$.

El inicio de operaciones de El Novillo permitió acrecentar la generación de energía eléctrica; la disponibilidad en 1950 era de $57 \mathrm{~kW}$, en 1964 pasó a $266 \mathrm{KV}^{29}$, flujo que se destinó al servicio privado, agrícola e industrial en las áreas más dinámicas del Estado (Hermosillo, Cd. Obregón, Guaymas, Navojoa) y permitió incrementar la superficie agrícola irrigada mediante la perforación de pozos.

\footnotetext{
${ }^{22}$ Oficio 331.8431 del 9 de marzo de 1961. Archivo Histórico del Agua (AHA). Fondo Documental de Aguas Nacionales. Caja 737. Expediente 8673. Legajo 01.

${ }^{23}$ Oficio 331.8431 del 9 de marzo de 1961. AHA. Fondo Documental de Aguas Nacionales. Caja 737. Expediente 8673. Legajo 01.

${ }^{24}$ Informe sobre la visita efectuada a las obras de la Presa del Novillo, fechado en Hermosillo el 3 de agosto de 1962 por el Gerente General de la zona Sur, Ing. Juan Muñoz Ramírez. AHA. Caja 737. Expediente 8673. Legajo 01.

${ }^{25}$ El Imparcial, 15 de enero de 1963.

${ }^{26} \mathrm{El}$ Imparcial, 4 de junio de 1964.

${ }^{27}$ El Imparcial, 12 de noviembre de 1964

${ }^{28}$ El Imparcial, 12 de noviembre de 1964

${ }^{29}$ Cárdenas, 2008, pp. 184-5; El Imparcial, 12 de noviembre de 1964.
} 
Tabla 1. Información técnica de grandes presas. Río Yaqui.

\begin{tabular}{lccccccc}
\hline \multicolumn{1}{c}{ PRESA } & Construcción & $\begin{array}{c}\text { Altura } \\
\text { cortina } \\
\mathbf{m t s} .\end{array}$ & $\begin{array}{c}\text { Área } \\
\text { subcuenca } \\
\mathbf{k m}^{\mathbf{2}}\end{array}$ & $\begin{array}{c}\text { Área de } \\
\text { Embalse } \\
\text { Hectá- } \\
\text { reas }\end{array}$ & $\begin{array}{c}\text { NAME } \\
\mathbf{h m}^{3}\end{array}$ & $\begin{array}{c}\text { NAMO } \\
\mathbf{h m}^{3}\end{array}$ & $\begin{array}{c}\text { Volumen } \\
\text { muerto } \\
\mathbf{h m}^{3}\end{array}$ \\
\hline $\begin{array}{l}\text { Lázaro } \\
\begin{array}{l}\text { Cárdenas } \\
\text { (Angostura) }\end{array}\end{array}$ & $1937-1941$ & 91.75 & 19,292 & 3,800 & $1,116.5$ & 703.4 & 0.0 \\
\hline $\begin{array}{l}\text { Álvaro } \\
\text { Obregón } \\
\text { (Oviáchic) }\end{array}$ & $1947-1952$ & 90 & 11,792 & 20,500 & $4,409.4$ & $3,023.1$ & 55.0 \\
\hline $\begin{array}{l}\text { Plutarco } \\
\text { Elías Calles } \\
\text { (Novillo) }\end{array}$ & $1958-1964$ & 133.80 & 40,368 & 10,241 & $3,512.0$ & $2,833.1$ & 602.6 \\
\hline & & & 71,452 & 34,541 & & & \\
\hline
\end{tabular}

Fuente: Comisión Nacional del Agua.

NAMO: Nivel de aguas máximas ordinarias. Coincide con el punto más alto del vertedor. NAME: Nivel de aguas máximas extraordinarias, es el nivel más alto que debe alcanzar el agua en el vaso bajo cualquier condición.

VOLUMEN MUERTO: es el que queda abajo del nivel de aguas mínimas de operación (NAMINO) y es un volumen del que no se puede disponer.

El Novillo cerró el ciclo de construcción de grandes presas en el río Yaqui $^{30}$ que, en conjunto y en un lapso relativamente corto -tres décadasmodificaron significativamente no sólo el entorno económico, sino también las condiciones históricas de desarrollo social y, ante todo, transformaron los ecosistemas en la cuenca del Yaqui. Antes de la construcción de las presas, las crecientes del río bañaban dos veces por año su llanura deltaica, que inicia en Cócorit; en el delta los yaquis aprovechaban pesca y caza, sus tierras eran fértiles y productivas; la última creciente ocurrió en 1949, cuando el río aún 'espumeaba' (Padilla, 2015). Actualmente los escurrimientos del río finalizan en la presa El Oviáchic.

\section{Impactos socio-ambientales}

La construcción de las grandes presas en el río Yaqui se inscribe en un proceso más amplio, ocurrido mundialmente e iniciado en el periodo de entreguerras, aunque tomó gran fuerza en los años de 1950 y 1960 (Barakat \&

\footnotetext{
${ }^{30}$ CONAGUA registra 52 grandes presas en el país; El Oviáchic está en el sitio 10 en orden de importancia, El Novillo en el 11 y La Angostura en el lugar 30. (Estadísticas, 2008).
} 
Arrojo, 2001). Según el Programa de Desarrollo de las Naciones Unidas ${ }^{31}$, el $60 \%$ de los cauces fluviales han sido "gravemente afectados". El impacto se extiende a cada uno de los ecosistemas asociados a los ríos (cauces, riberas, deltas, estuarios, humedales y acuíferos). Es muy reciente la preocupación por el deterioro ambiental generado por las grandes presas, algunos de cuyos efectos son ya irreversibles. Los impactos negativos que la construcción de una gran presa trae consigo son de gran calado; le acompañan afectaciones en flora y fauna asociadas a la cuenca, desplazamiento forzado de gente, sedimentación, pérdida de fertilidad en las tierras cultivables, calidad del agua e incremento en la sismicidad. El levantamiento de grandes presas en el río Yaqui ha ocasionado transformaciones de alto costo social y ambiental que, como en otras partes del país y el mundo, no fueron visualizados al planificar y ejecutar las obras de construcción (Flores, 2001).

Por lo que se refiere a desplazamientos forzados, el impacto fue diferente para cada una de las presas. La Angostura fue construida en la sierra alta al este de Sonora, área fronteriza poco poblada; el sitio cercano más importante es Nacozari, centro minero productor de cobre. A la vera del río Bavispe (afluente del Yaqui y alimentador de La Angostura) se ubican numerosos pueblos (como Huachinera, Bacerac y Bavispe) presumiblemente poco afectados; aguas abajo del reservorio los efectos fueron severos y duraderos en los pueblos de Óputo, Huásabas y Granados. El embalse inundó el Valle de Teras y su centro poblacional Casa de Teras, ejido comunal en manos de 59 familias. De acuerdo con Evans (2006, pp. 6465), la CNI en 1940 quemó las casas de los ejidatarios, pagó a los residentes 46.200 pesos y les ofreció trasladarse al valle del Yaqui, sitio en el que la misma comisión había adquirido tres mil hectáreas para que refundaran el ejido. Además, numerosos ejidatarios y pequeños agricultores de Óputo, Granados y Huásabas enfrentaron las consecuencias por el cambio de dirección de la corriente del río, inclusive la interrupción del flujo de agua mientras se llenaba el embalse; por primera vez veían el río seco y debieron suspender las actividades agrícolas.

Por otra parte, el embalse de la presa El Oviáchic inundó el antiguo pueblo de Buenavista, fundado como misión jesuita en 1619 aunque, al ubicarse en la frontera étnica entre yaquis y pimas bajos, cambió su condición a resguardo militar; en 1765 fue establecido allí el presidio San Carlos de Buenavista, para 1820 tenía el rango de villa y, con Cumuripa, era

\footnotetext{
${ }^{31}$ Informe World Resources 2000-2001: People and Ecosystems: The Fraying Web of Life, publicado por el Programa de Desarrollo de las Naciones Unidas (UNDP), el Programa de Medio Ambiente de las Naciones Unidas (PMANU, UNEP), el Banco Mundial y el Instituto de los Recursos del Mundo (WRI), citado por Barakat y Arrojo (2001). Disponible en http://www.wri.org/sites/default/files/pdf/world_resources_2000-2001_people_and_ecosystems.pdf
} 
de los poblados no indígenas más importantes de la zona. Su importancia decreció a principios del siglo XX, al impulsarse las obras de colonización de la Compañía Constructora Richardson y poblarse el sitio que llegaría a ser Ciudad Obregón. Para cuando se construyó la presa El Oviáchic, los pobladores de San Carlos de Buenavista se trasladaron a un nuevo sitio a pocos kilómetros de la presa ${ }^{32}$.

El desplazamiento de gente más importante fue provocado por la construcción de El Novillo; tres antiguos pueblos (fundados por jesuitas entre 1622 y 1629) se 'ahogaron' bajo el embalse. Al igual que con la construcción de las dos grandes presas anteriores sobre el río Yaqui, tampoco a los habitantes de Batuc, Tepupa, Suaqui y San Pedro de la Cueva se les pidió opinión sobre la ejecución de tan magna obra; no obstante, preocupados por su incierto destino, los vecinos (alrededor de 6.000) levantaron su voz para que sus propuestas fueran escuchadas; solicitaron en primer término al presidente de la república la reubicación de la presa, el 2 enero de 1959 (Enríquez, 1989, p. 242) al no conseguirlo, constituyeron comités pro-defensa en cada uno de los pueblos, y demandaron en agosto de 1959 al gobernador del estado, que se previeran las estrategias para darles apoyo y pudieran enfrentar "un radical cambio de vida" 33.

Los sitios que eligieron para ser reubicados eran aquellos que podían garantizar la continuidad de su forma de vida "como pueblo": valles de Guaymas, Yaqui, Mayo o en el río Sonora (Enríquez et al., 2015). Al advertir que sus propuestas eran consideradas 'irrealizables' por la CFE, plantearon al gobernador de Sonora el 9 de abril de 1962:

[...] los habitantes de los pueblos [...] están pasando por una etapa crucial de su existencia; están viviendo momentos de angustia e incertidumbre [solicitan tome] muy en cuenta [a] estas gentes que serán sacrificadas en aras del progreso [...] al tener que abandonar obligadas por las circunstancias, sus viejos lares, tradiciones y costumbres para ser trasladados a un medio extraño, quizá hostil al principio, sacrificio que muchos en su ignorancia no encuentran justificado, pero consideran que al tener involuntariamente que abandonar su terruño les asiste mucho derecho para aspirar a un mejoramiento de vida en justa retribución $[\ldots]^{34}$

\footnotetext{
32 "Algo de historia" 4 de abril de 2005. http://oviachic.blogia.com/2005/040403-algo-de-historia.php

${ }^{33}$ El Imparcial, 22 de agosto de 1959.

${ }^{34}$ Oficio del 9 de abril de 1962 enviado por el Comité Directivo de los pueblos al gobernador Luis Encinas. AGES Expediente citado.
} 
En septiembre de 1962 el gobierno del estado de Sonora propuso a los vecinos un plan: ${ }^{35}$ podrían elegir entre recibir dotación de tierras en el distrito de riego del río Mayo o ser indemnizados por sus propiedades; adicionalmente, se facilitaría a los interesados su alistamiento en el Programa de Braceros, cuyo centro de contratación estaba en Empalme, además de gestionar con el gobierno federal que la presa se poblara con "la especie más apropiada de peces, para beneficio de los moradores de la región." El plan mostró su eficacia para organizar el desalojo de los pueblos, pero muchos de los supuestos beneficios que tendrían los expulsados no llegaron a concretarse. Para los transterrados vendrían años muy difíciles; los más reacios a abandonar su terruño fundaron pueblos nuevos a poca distancia de los antiguos, otros emigraron a las ciudades costeras, principalmente Hermosillo; grupos numerosos salieron con rumbo a Estados Unidos en calidad de braceros; los menos numerosos aceptaron establecerse en la región del Mayo. El deceso oficial de los pueblos lo dictó la ley número 87, publicada el 24 de junio de 1964.

Además de violentar las condiciones de vida de importantes asentamientos humanos, el represamiento del río Yaqui ha tenido notable incidencia en el proceso de renovación de agua dulce, en el que las presas constituyen uno de los principales factores. La disponibilidad de agua dulce depende de la "integridad ecológica de los ecosistemas dulceacuícolas" que son, paradójicamente, los más perjudicados por la acción humana, por lo que contribuyen a la escasez del agua (Martínez, Búrquez y Calmus, 2012, p. 291). Otro cambio medioambiental ocasionado por el llenado de embalses es la inundación de bosques y matorrales, así como el desplazamiento de la fauna local; en el caso de las tres presas sonorenses el área inundada asciende a 28,265 ha. Búrquez y Martínez-Yrízar (1997) registran que en los deltas de los ríos Yaqui y Mayo desaparecieron más de un millón de hectáreas de mezquite y bosques ribereños de sauce y zarzales cuando entraron en operación las grandes las presas. Un vecino de Buenavista narró cómo, para construir la presa el Oviáchic, la constructora:

[...] hirió los montes. En cuatro meses unas cinco mil personas nos quitaron la pequeña historia del pueblo, del río y de nuestros brazos. El espantadero de animales hacia otras madrigueras apenas si lo vimos, las alamedas fueron aserradas y los mezquitales hechos carbón. (Murrieta S.A, pp. 200-201)

\footnotetext{
35 "Plan de solución al problema de la inundación de los pueblos de Suaqui, Tepupa y Batuc por las aguas de la presa del Novillo" 26 de septiembre de 1962. Archivo General del Estado de Sonora (AGES) Expediente $412.6^{\prime \prime} 58^{\prime \prime} / 3$.
} 
La inundación de bosques y el gradual proceso de degradación del suelo en las cuencas de los ríos, han dado como resultado "la disminución de la capacidad de recarga, tanto de las aguas superficiales como de las subterráneas" a la vez que se ha incrementado la erosión de la tierra aun en zonas protegidas, como la Reserva Forestal y Refugio de la Flora y Fauna Ajos-Bavispe, lugar en que nace el río Sonora (Análisis, 2005).

El cambio más significativo derivado de la construcción de una presa es la conversión del régimen hidrológico e hidráulico que, en su condición natural, se caracteriza "por una velocidad significante, el mezclado y turbulencia el agua, sedimentos suspendidos y arrastrados y una alta tasa de aireación" mientras en el embalse se convierte en un régimen lacustre, con las características opuestas; aguas abajo de la presa ocurre un cambio en el flujo de la corriente, que lleva aparejados cambios morfológicos, físicos y químicos con alto impacto en los ecosistemas conectados al río (Flores, 2001, p. 145; Cotler, 2010, p. 126).

Un problema con efectos múltiples y severos lo constituye, sin duda, la retención de sedimentos en las presas, cuyas secuelas son la pérdida de capacidad de almacenamiento, degradación del lecho del río y decrecimiento en los niveles de agua; alteraciones en los sistemas ecológicos locales y aguas abajo del embalse-pues el bajo contenido de sedimentos reduce la productividad agrícola en las tierras- y alteraciones en las playas, que dejan de alimentarse de las arenas trasladadas por los ríos (Flores, 2010).

En su perspectiva optimista, los funcionarios gubernamentales y empresarios agrícolas que promovieron el triple represamiento en el río Yaqui, previeron que además de la ampliación de la frontera agrícola, se elevaría la productividad de las tierras hasta entonces naturalmente fértiles. Desafortunadamente no fue así; aun antes de que entrara en operación la presa El Novillo, el valle del Yaqui mostraba ya niveles alarmantes de alcalinidad e incremento en la salinidad, condiciones que llevaron a la necesidad de recurrir a fertilizantes químicos, plaguicidas y herbicidas, que han contaminado aun el agua potable, ocasionando graves problemas de salud, sobre todo en los niños yaquis (leucemia, cáncer).

Según señala la Comisión Estatal del Agua, los más relevantes problemas de contaminación en Sonora se localizan en los cauces de los ríos y en zonas de riego con aguas superficiales, cuyos drenes, además, "son receptores de descargas de centros de población, industrias, actividades pecuarias y las aguas de retorno agrícola"36. En el valle del Yaqui están contaminadas las aguas de riego como resultado de las prácticas agrícolas

\footnotetext{
${ }^{36}$ El distrito de riego del valle del Yaqui cuenta con 18 drenes principales, 234 secundarios y 1007 terciarios; todos descargan al mar "un volumen promedio anual de 521 millones de m3 de aguas residuales sin tratamiento previo." (Arreola, 1995, p. 34).
} 
y el uso de agroquímicos; los excedentes contaminados son descargados en el mar, sumándose a los acumulados en los centros de camaronicultura y ostricultura (Luna, 2007; Análisis, 2005) ${ }^{37}$.

En su descripción sobre las regiones hidrológicas prioritarias, la CONABIO registra un importante proceso de desertificación en la región río Yaqui - cañada de Basaseachic. A la contaminación por el uso de agroquímicos, añade los desechos mineros en la parte alta de la cuenca y los graves efectos del sobrepastoreo, la alteración del patrón hidrológico, la alteración de la calidad del agua en la planicie costera, la intrusión salina, la erosión de la cuenca, el azolvamiento de las costas y la erosión en la costa debido a las presas.

En 1964, al inaugurarse la presa El Novillo, se vaticinó que mediante el recursode "modernastécnicas [sería] factiblequeen el futuroelmar[perdiera] totalmente las aportaciones del río Yaqui" ${ }^{38}$. Esto, lamentablemente ocurrió tres décadas después; si bien el caudal disminuyó desde 1952 debido a la entrada en operaciones de La Angostura, fue hacia 1992 que el río dejó de fluir por territorio yaqui, justo cuando se construyó el acueducto GuaymasEmpalme ${ }^{39}$, que también ha exacerbado la afectación y contaminación en el delta del Yaqui, donde debía desembocar en el golfo de California.

\section{Para concluir}

Hemos procurado describir los diversos factores interactuantes en el escenario histórico en que tuvo lugar el triple represamiento del río Yaqui, así como la alteración ecológica que le ha acompañado. Las amplias expectativas subsumidas en el proyecto hidráulico impulsado por los gobiernos federal y estatal -apoyado por los empresarios agrícolas- en la primera mitad del siglo $X X$, se lograron en parte: la frontera agrícola se expandió, la agricultura se modernizó y el aprovechamiento del recurso hídrico generó, sin duda, grandes riquezas, aunque se repartieron de manera desigual; no obstante, el costo de tan espectaculares logros ha sido alto en lo que se refiere al impacto socioambiental.

\footnotetext{
${ }^{37}$ Uno de los sitios afectados en la costa es el manglar Estero Los Lobos (ubicado en Las Guásimas), con una superficie de 5,737 has., relevante para el ciclo biológico de especies marinas y por su función como corredor biológico para algunas especies de aves. Su deterioro tiene impacto, entre otras cosas, en los volúmenes de pesca, dado que en el Golfo de California, éstos se relacionan con el buen estado de los manglares (Acosta-Velázquez \& Vázquez-Lule, 2009).

${ }^{38}$ El Imparcial, 12 de noviembre de 1964. En la parte baja de la cuenca del río Yaqui, "sólo existe el antiguo cauce del río, con presencia escasa de agua, en época de lluvias, y algo de flujo base que se alcanza a observar en el tramo entre la presa derivadora Chiculi y el poblado de Chumampaco (unos seis kilómetros). De ahí hasta el litoral costero se tienen unos $15 \mathrm{~km}$ de cauce seco." (Luna, 2007, p. 124).

${ }^{39} \mathrm{Su}$ objetivo es abastecer de agua potable al puerto de Guaymas y la zona turística de San Carlos; el acueducto tiene una longitud de $120 \mathrm{~km}$.
} 
Si bien el control y administración del caudal del río Yaqui permitió el incremento en el número de hectáreas irrigadas en el valle, así como un alza notable en la productividad, los sistemas de canalización y riego han tenido alta incidencia en la pérdida de fertilidad de la tierra, así como en el abatimiento de acuíferos y la intrusión salina. La interrupción del caudal, por otro lado, dejó sediento el territorio de los yaquis que, teniendo legalmente derecho al agua, carecen de ella o, cuando pueden disponer del recurso, está contaminado por agroquímicos. De igual manera se han afectado manglares y humedales en la costa, con secuelas en la flora y la fauna marina costera, así como en la biodiversidad a lo largo del menguado cauce del río.

Es de esperarse que tales impactos se magnifiquen pues existen nuevas presiones sobre las aguas de la cuenca del río Yaqui. La más reciente es el tendido del acueducto Independencia ${ }^{40}$, un canal entubado de $120 \mathrm{~km}$ que traslada el recurso hídrico desde la presa El Novillo a la ciudad de Hermosillo, promovido por sectores empresariales del ramo inmobiliario, de la construcción, comercial e industrial de la capital del estado, con la oposición de los empresarios agrícolas del valle del Yaqui, sectores productivos del municipio de Cajeme e indígenas yaquis. Este conflicto por el agua expresa una nueva tendencia: redistribución del agua en beneficio de las ciudades y afectación a las áreas agrícolas, rurales e indígenas; se incrementa asimismo el impacto negativo en el medio ambiente (Moreno, 2015).

El Acueducto Independencia es expresión de un severo problema en Sonora, la escasez de agua. Los opositores a dicha obra argumentan que no es viable enviar agua del río Yaqui a Hermosillo "pues aún no está resuelto el abastecimiento de agua en el valle del Yaqui" ${ }^{41}$. Para remediar tal situación, han buscado recuperar un viejo proyecto, el Plan Hidráulico del Noroeste (PLHINO), mediante el cual se aprovecharían "los grandes volúmenes de agua que se tiran al mar entre Mazatlán y Nayarit", mismos que se transportarían al norte de Sinaloa y sur de Sonora con el propósito de extender la frontera agrícola y dar solución a la escasez de agua en las grandes ciudades de Nayarit, Sinaloa y Sonora ${ }^{42}$.

Estamos, pues, antenuevos embates hacia el entorno medioambiental y nuevos retos para la acción social.

\footnotetext{
${ }^{40}$ Ver Informe de los impactos provocados por la implementación del acueducto Independencia a cargo del Gobierno del Estado de Sonora. (2013) México. UNAM-FCPYS. https://observacionconsultayaqui. files.wordpress.com/2013/12/informe-yaquis.pdf

41 “Rechaza acueducto comité Pro PLHINO”. En Infocajeme. 15 de enero de 2010. http://www.infocajeme.com/general/2010/01/acueducto-no-plhino-si/

42 "Dan fracciones parlamentarias del Congreso apoyo al PLHINO". Dossier Político. 1ํ de noviembre de 2007. http://www.dossierpolitico.com/vernoticiasanteriores.php?artid=27885\&relacion=dossierpolitico
} 


\title{
Fuentes
}

\author{
Archivos \\ Archivo Histórico del Agua (AHA) \\ Archivo General del Estado de Sonora (AGES) \\ Hemerografía \\ Diario Oficial de la Federación \\ Periódico El Imparcial. Hermosillo Sonora. \\ Periódico El Pueblo. Hermosillo Sonora.
}

\section{Referencias bibliográficas}

Aboites Aguilar, L. (1998). El agua de la nación. Una historia política de México (1888-1946) México: CIESAS.

Acosta-Velázquez, J. y Vázquez-Lule A.D. (2009). Caracterización del sitio de manglar Estero Los Lobos. Comisión Nacional para el Conocimiento y Uso de la Biodiversidad (CONABIO).

Autor. Análisis sobre el uso y manejo de los recursos hidráulicos en el estado fronterizo de Sonora. (2005). Gobierno del Estado. Comisión Estatal del Agua.

Arreola Lizárraga, J.A. (1995). Diagnosis ecológica de Bahía de Lobos, Sonora, México (Tesis Maestría). IPN-CICIMAR. La Paz B.C.S.

Barakat, M. y Arrojo Agudo, P. (2001). Impacto ambiental de las grandes presas en cursos bajos, deltas y plataformas litorales: el caso de Aswán. II Congreso Ibérico sobre Planificación y Gestión de Aguas. Zaragoza. Recuperado de

http://ocw.atica.um.es/ciencias/ecologia/lectura-obligatoria-1/arrojo-atwi.pdf

Búrquez, A. and Martínez-Yrízar, A. (1997). Conservation and landscape transformation in Sonora, México. Journal of the Southwest, 39(3/4), Dry Borders: Binational Sonoran Desert Reserves Autumn - Winter, pp. 371-398.

Cárdenas García, N. (2008). Agricultura comercial, industria y estructura ocupacional en Sonora (1900-1960). Región y Sociedad XX(41). pp. 175-197.

Castro, H. (2013). La cuestión ambiental en geografía histórica e historia ambiental: tradición, renovación y diálogos. Revista de Geografía Norte Grande, 54: 109-128.

Cerutti, M. (2015). La agriculturización del desierto. Estado, riego y agricultura en el norte de México (1925-1970). Apuntes, XLII(77). pp. 91-127. Centro de Investigación de la Universidad del Pacífico.

Cotler, H. y González, D.I. (2010). Sedimentación potencial de presas. En: H. Cotler Ávalos (Coord.), Las Cuencas Hidrográficas de México, (pp. 124-127). Secretaría de Medio Ambiente y Recursos Naturales, Instituto Nacional de Ecología Fundación Gonzalo Río Arronte,

Dabdoub, C. (1995). El Valle del Yaqui. Hermosillo, Gobierno del Estado de Sonora: Editor José Rómulo Félix Gastélum.

Enríquez Licón, D.E. (1989). Batuc, Tepupa y Suaqui: de la tauna a la hidroeléctrica En: Memoria del XIII Simposio de Historia y Antropología de Sonora. Hermosillo: Universidad de Sonora.

Enríquez Licón, D.E., Romero Gil, J.M., Lorenzana Durán G. y Cruz Loustanau, Tesia. (2015). La hidroeléctrica Plutarco Elías Calles (El Novillo, Sonora) y el Plan Nacional de Electrificacion. En: III Simposio Internacional Historia de la electrificación. Ciudad de México.

Escobar Ohmstede, A. (Com.). (2013). La ecología política, la ecología cultural y la historia ambiental a través de Relaciones. Estudios de Historia y Sociedad. México. El Colegio de Michoacán. Fideicomiso Felipe Teixidor. 
Evans, S. (2006). La angustia de La Angostura: consecuencias socioambientales por la construcción de presas en Sonora. Signos Históricos, 16, 46-78.

Flores Cervantes, J.H. (2001). Impactos ambientales de presas y bordos (Tesis). Facultad de Ingeniería. UNAM.

García Ugarte, M. (1995). La propuesta agraria de Venustiano Carranza y los sonorenses (19191929). En: Estudios. Filosofía-historia-letras. ITAM. Verano. Recuperado de http:// biblioteca.itam.mx/estudios/estudio/letras41/texto3/sec_1.html

Lerma Rodríguez, E. (2014). Notas para el análisis de la resistencia yaqui en contra del Acueducto Independencia. Sociológica, año 29 (82), 255-271.

Los Presidentes de México ante la Nación 1821-1966. (1966). México: Imprenta de la Cámara de Diputados, tomos III y IV.

Luna Escalante, G. (2007). Derechos, usos y gestión del agua en el territorio Yaqui (Tesina). Especialidad en Gestión Integrada de Cuencas Hidrológicas. El Colegio de Sonora. Hermosillo.

Martínez Alier, J. (2014). Entre la Economía Ecológica y la Ecología Política. Noviembre. www. sinpermiso.info

Martínez Yrizar, A., Búrquez, A. y Calmus, T. (2012). Disyuntivas: impactos ambientales asociados a la construcción de presas. Región y Sociedad, Núm. Esp. 3.

Montané Martí, J.C. (2004). Agua y agricultura en la Sonora colonial. En: El agua y la agricultura en la historia de Sonora. Hermosillo. Sociedad Sonorense de Historia, Centro de Investigación en Alimentación y Desarrollo.

Moreno Vázquez, J.L. (2015). Despojo de agua en la cuenca del río Yaqui. Hermosillo: El Colegio de Sonora.

Murrieta, M. (s.f.). Por el milagro de aferrarse. Tierra y vecindad en el valle del Yaqui. Hermosillo, El Colegio de Sonora-Instituto Tecnológico de Sonora-Instituto Sonorense de Cultura.

Okada, A. (2000). El impacto de la Revolución Mexicana la Compañía Constructora Richardson en el Valle del Yaqui (1905-1928). Historia Mexicana, L (1).

Padilla Ramos, R. (2016). El río en la vida de los yaquis. Diario de Campo. INAH Sonora.

Padilla Calderón, E. (2015a). El valle de los yaquis y la colonización 'oficial' en un contexto de guerra, 1880-1900. En: J.M. Medina B. y E. Padilla (Coord). Violencia interétnica en la frontera norte novohispana y mexicana. Siglos XVII-XIX. Hermosillo: El Colegio de Sonora, El Colegio de Michoacán.

Padilla Calderón, E. (2015b) Naturaleza y cambio social. Un acercamiento a través de la exploración de las crecientes del Yaqui. En: XL Simposio de Historia y Antropología, Historia Ambiental. Universidad de Sonora.

Pérez de Ribas, A. (1992). Historia de los triumphos de nuestra santa fee entre gentes las mas barbaras, y fieras del nuevo Orbe. Año 1945. México. Editorial Siglo XXI. (Estudio introductorio, notas y apéndice de Ignacio Guzmán Betancourt).

Quijada, C.A. (2004). La importancia del agua en la historia prehispánica de Sonora. En: El agua y la agricultura en la historia de Sonora. Hermosillo. Sociedad Sonorense de Historia, Centro de Investigación en Alimentación y Desarrollo.

Regiones hidrológicas prioritarias, CONABIO. 2008. http://www.conabio.gob.mx/conocimiento/ regionalizacion/doctos/rhp_016.html

Sánchez Rodríguez, M. y Eling, H.H. (coords). 2007. Cartografía hidráulica de Guanajuato. México: El Colegio de Michoacán-Consejo de Ciencia y Tecnología Guanajuato.

Worster, D. (2008). Transformaciones de la Tierra. Montevideo. Coscoroba Ediciones, Biblioteca Latinoamericana de Ecología Política. Selección, traducción y presentación de Guillermo Castro H. 